\title{
Student Assessment in Sociopolitical Education Subjects and Its Value Basis in Relation to Society
}

\author{
Georgios Bikos ${ }^{1,2,3}$ \\ ${ }^{1}$ School of Humanities, Hellenic Open University, Patras, Greece \\ ${ }^{2}$ Pedagogical Department of Primary Education, National and Kapodistrian University of Athens, Athens, Greece \\ ${ }^{3}$ Department of Education, School of Pedagogical and Technological Education, Athens, Greece
}

Email address:

g_bicos@yahoo.gr

\section{To cite this article:}

Georgios Bikos. Student Assessment in Sociopolitical Education Subjects and Its Value Basis in Relation to Society. Education Journal. Vol. 7, No. 4, 2018, pp. 100-107. doi: 10.11648/j.edu.20180704.15

Received: August 30, 2018; Accepted: September 21, 2018; Published: October 22, 2018

\begin{abstract}
In the main part of this text an analysis of the objectives expected as part of the assessment of a student's "performance" in sociopolitical education subjects is provided. At the same time, a detailed explanation is given of how relevant the concept of a student's "performance" is, as regards many of his/her qualities assessed through the assessment process in question. Initially, an attempt is made to explain how and why each assessment, either of students or the learning process, is linked with values deriving from the dominant culture at the time and aligned linearly with the dominant-ruling perceptions in the field of education and society. The analysis is based on a bibliographic approach with the most significant of its secondary objectives being to promote the link that the teaching method should have with the assessment of a student's performance. Thus, by elaborating on the subject in such a way, useful recommendations are indirectly made to the teacher of sociopolitical education subjects concerning even the key objectives that his teaching approach, methods and content should exhibit, as far as the students are concerned, both in primary and secondary education.
\end{abstract}

Keywords: Social Values, Assessment, Teaching Process, Skills, Competencies, Critical Sociopolitical Thinking, Creative Thinking

\section{Introduction}

First of all, it is commonly held that assessment in education has always been linked, explicitly or implicitly and consciously or unconsciously, with the cultural reality within the framework of which it is established and the social reality it expresses, "serves" or attempts to improve, on the basis of certain models and certain "plans" and/or "visions" created by the majority of society members or those at the helm of society (i.e. its social leaders, its intellectual elite or those that hold the "authority" which shapes its educational system). Therefore, the first step taken in this text is to explain the link between sociocultural data and the reality (see theory and practice) of educational assessment.

In parallel to what has just been mentioned, it is also true that: In recent decades there has been extensive discussion about a citizen's education or, rather about citizenship [11, $18,1,6]$; and often discussion is focused on something more special: more specialised education on active citizenship or the quality of the democratic citizen or the citizen of democracy. Thus, even if citizenship -as analysed elsewhere [4]- is endorsed at school also through subjects of a nonpolitical content (see, for example, Nussbaum's excellent and thorough analysis [21] about how somebody learns to be a democratic citizen through studying subjects in the field of Humanities), an indicator of how democratically organised tomorrow's society will be and what percentage of its citizens will be active, i.e. participatory in sociopolitical developments, is also the content of social and, mainly political education subjects taught mainly in primary and secondary education. But even if it is clear that this "content", and the respective Curriculum of these subjects promotes a democratic and participatory political culture, this fact alone cannot inspire optimism for the near future if there are no indicators, or at least indications, of the two facts that follow: first, that the majority of students assimilates this very "content" of the given culture on a satisfactory or 
relatively satisfactory degree and, second, that students acquire the competencies and skills necessary to act as active and democratic adult citizens through school teaching.

This is, however, how the issue of assessing what students learn from these subjects, which have a purely sociopolitical content, comes to the foreground. And one of the key objectives of this text is to present the particular educational, pedagogic and politicological criteria which (which are associated with popular democratic political and social values, but also with a similar democratic political culture) on the basis of which this assessment should take place so as to valuate, in the fullest possible manner, how participatory and democratic the political education that today's youth acquires through these school subjects really is. Finally, through the analysis outlined in this text, another fact is indicated: this assessment will also have a character that would necessarily express certain political-social ethics and a culture of a specific content, therefore it will be incomplete if it relates only to a "content" of knowledge, student competencies and skills.

\section{Main Part}

\subsection{The Logical Basis, Value Origin and Social Function of School Assessment}

Before commencing our analysis, however, it is deemed appropriate to approach the term assessment ( $\alpha \xi_{10} \lambda$ ó $_{\eta} \sigma \eta$ in Greek) from a more general and theoretical perspective, based on the content of its two constituents ( $\alpha \xi i \alpha$ and $\lambda$ ó $\gamma$ o $\varsigma$ in Greek): value and discourse/reason. Therefore, assessment constitutes a piece of discourse or a verbally expressed conclusion (hence it forms an assessing judgment or an assessing description) regarding the value (or quality) of a person, thing/“subject matter"/feature [19] -which may have the form of an "output", "result" or creation-, condition or process [12]. And focusing, first, on the second constituent of the Greek word for assessment (namely discourse/reason), the following can be observed: assuming that this constituent does not only refer to discourse, but also to Reason, that is to Logic, then it can be realised that it refers to a logically structured mindset (i.e. a mindset founded upon a logic relation, and/or a cause-effect relation) on the basis of which assessors (should) conduct the act of assessment, in accordance with certain specific criteria [19]. Thus, assessment is conducted on the grounds of a justification (on the grounds of the above set criteria), which corresponds to a kind of determinism with particular structure and logic.

So this "logical" basis of assessment is the key argument of those who attempt and aim to attribute to it the objective character it would rather or should exhibit (or, to be more exact, to appear to exhibit in the eyes of the public) so as to be legalised as a common practice without being questioned either on the basis of its prestige or value or even its initiator's - i.e. the assessor's - intention/purpose. And when some attempt to attribute an "objective" character ${ }^{1}$ to it, they attempt to minimise or eliminate its "subjective" character, which derives from the assessor and is due to his/her (special) personality. (According to many experts, however, every assessment has a subjective character [28].)

But it is time to return, at this point, to the first constituent of the Greek word for assessment, which is value.

It is quite interesting to note that the word value has a dual meaning: first, it is related with the evaluation -which is normally applied to the base of a graded continuum/axis- of certain features/characteristics or qualities of an element, thing, condition, person, and, second, it is associated -no matter how unnoticeable this may be- with one or more (usually interrelated) social values. And social values are defined as those positions of the overwhelming majority of a/the society which are not only considered to be important/meaningful for this society (and also for every individual member of it), but also appropriate to shape the daily acts and general behaviour of people/individuals in order to secure the smooth operation and progress of society.

So how are these two meanings of the word value combined/connected? As follows: Using assessment people evaluate or valuate ${ }^{2}$ the degree to which an "element", person, "product" or situation features a certain characteristic that constitutes a "value" for society - i.e. (a) social value. Thus, assessment reveals/indicates how socially valuable an element, condition, person or "output"-"product" is - in other words, it reveals the social value and social usefulness that the public opinion attributes to it.

So, the assessment that concerns the student should highlight what is considered to be important and valuable by the society and also by the corpus of people which also includes teachers and scientists $[12,26,24]^{3}$, and also

\footnotetext{
1 Because it is commonly accepted that logic is not shaped by just one person, nor does it express one or two subjects. On the contrary, it is "curved" either from the basic elements of the way of thinking, which is common for the overwhelming majority of people, or by society almost as a whole, (therefore it acts rather as a collective-social convention) or, as others claim, by all scientists and philosophers in society. Hence, in any case, it constitutes a non-subjective, objective reality even if this reality is conventional, i.e. the product of a convention. (Besides, every social convention is an objective reality, as Durkheim would say, since, first, it is not dependent on any separate individual and, second, it is imposed equally on all, or almost on all, individuals.)

2 In an effort to highlight the difference between the words-terms evaluation and valuation, it should be noted that the term valuation implies the subjective element of assessment and that assessment expresses certain personal qualities of the assessor. On the contrary, the term evaluation is more associated with the "objective" character and the "objective" features of assessment (which are often called "countable" even though the assessment process almost always includes features which are uncountable). (However, Kassotakis [12] says that when many authors use the term evaluation they mean school performance measurement.)

3 The society, e.g., believes that the most important of all that the school should teach to children and the youth, is to be honest, and also dynamically effective in the field of social and financial competition of our times. Teachers, on the other hand, as pedagogists, believe that the most important thing that the school should teach to students is to be amiable, hardworking, love learning and making progress, respect the elder and appreciate education and educated people. And scientists believe that the main thing that the school should teach to its graduates is to write texts and prepare assignments that would be well-structured and wellcompiled, in terms of language, and think rationally and not be easily convinced
} 
whatever "important"-valuable (s)he "learnt" from the "lesson" (i.e. through teaching, the activities completed in class with a learning objective, or his/her personal studying/practice outside the school class, as a result and on the basis of (i) the syllabus and (ii) the demands of his/her teacher).

\subsection{What Is the Assessment of the Learning Process About}

When the term assessment of learning is used here, it means the assessment of the learning process, that is the evaluation of whether and to what extent all processes and "acts that make up what we call teaching" manage to teach something to the student.

Nevertheless, it may also mean the following: the evaluation of whether and to what extent the whole teaching process managed to make students learn some specific pieces of knowledge, or develop some specific attitudes, abilities or skills, ${ }^{4}$ which are included in the teaching objectives of the module presented to them. Hence, if someone attributes this content to the assessment of the learning process, they can evaluate, through it, in essence, the degree to which the student learnt (or the teacher managed/achieved to make the student learn) all those teaching "contents" that the teacher purposefully attempted to teach him/her. (But, on the basis of what was stated previously, these very teaching "contents" (will) logically relate not only to socially important knowledge or socially important skills and/or competencies, but, in a certain, more or less apparent way, they will also refer to certain social values.)

\subsection{Educational and Social Determining Factors When Assessing the Learning Process}

Since, however, the learning process involves two poles, i.e. the teacher and the student (therefore through its assessment both the ability of the former to teach and the latter to learn are assessed), would be advisable to approach some of its crucial parameters more analytically. Some of them are more related to the teacher, while others are more related to the student.

First, let's analyse the constituents behind the assessment of the learning process, as this is accomplished by the teacher, to ascertain its deeper relationship with what we call values.

So, note, initially, that this assessment is a) conducted in terms of certain models -e.g. that of the "excellent" or "keen" student- which relate to the subject being taught, or some other performance models that relate to the student. ${ }^{5}$ However, as is known, behind every model, there are always

with anything that is not based on a scientific method of analysis and rational documentation.

4 Skills are different from abilities/competencies, even though quite a few texts some even related to Teaching- refer to the two terms in a way that makes the reader consider them either as almost or totally synonymous, or not realise that there are differences (not to mention important ones) between them.

5 Hence, the comparative element is co-present in school assessment [20] since, as part of its application, each student is either compared (unconsciously) with such a model, or (consciously or unconsciously) with one or some of his/her "excellent" or, more rarely, significantly lower performing classmates. one or more values on the basis of which the content and qualities that define it are determined. Hence, these models are based on values and/or value options of the society, the majority of its members or (to use a term by Bourdieu), those who shape its intellectual/educational capital.

b) conducted in terms of the objectives set as part of the teaching module or teaching hour [21]. (It may also be applied, to a certain extent, on the basis of the general purpose of the lesson $[14,24,11,5]^{6}$ ). And these objectives are set i) on the basis of the special type of the lesson. E.g. in a lesson that offers knowledge about the organisation of sociopolitical life, it is almost impossible for the teacher, not to promote, on the basis of the Syllabus, also his students' critical thinking $[1,4]$. Therefore, if a student can never articulate some form of critical discourse in class or include it in the text of a written assignment, then as part of the assessment the teacher is called upon to make (s)he can only regard it as something negative. This setting of objectives is also defined iii) on the basis of the content of each specific module of the subject being taught. E.g. teaching the different political systems requires another kind of understanding, whereas teaching the various theories and ideologies demands a deeper, more theoretical, more reflecting and more critical approach - therefore, the assessment criteria are respectively different for a student's performance.

And c) conducted on the basis of the framework composed by the school-social and legislative reality within which the teacher works and teaches - see (i)the current educational legislation (which also includes the Syllabi), (ii)the technical and building infrastructure of schools ${ }^{7}$, (iii)the culture of the society where the school is located and operates (: sociocultural "environment") and, mainly, (iv) the students' general "profile" (see their perception identity, their cultural, educational and socioeconomic profile, their aims, desires and interests).

Hence, in conclusion, the assessment of the learning process is accomplished on the basis of the principle of socioeducational models that concern the socially desired model of student (: principle of the ideal), the principle of setting objectives-purposes for every subject taught (: principle of setting objectives and programming teaching) and the principle of limitations of the (school-social and legal-institutional) reality (: principle of terms and limits of reality/principle of realism).

\subsection{The Various Forms of Student "Performance", Competencies and Capabilities Assessed by Teachers}

Turning, now, to the pole of the student, note the

6 About the difference between the teaching objectives of a module -that relates to magnetism, for example- and the general teaching purposes of the subject which is, for example, Physics in Senior High School-, see, for example, [23].

7 To realise how important ii often is, we should mention that whether the teacher will teach a group of 35 or 17 students depends on a combination of $i$ and ii. Hence, first, surely ii affects $i$ and, second, the combination of these two can act as a catalyst (in the approach and method of teaching and, as a result also) upon the teacher and the educational task-learning result, so also upon the learning process. 
following: The assessment of the learning process is accomplished in three different teaching stages. Thus, based on the time when it is accomplished, we have three kinds of assessment: The diagnostic/initial assessment which is held before teaching commences $[12,11,5,29,13,14,24,26,21$, 17], the formative assessment which is conducted during teaching $[12,11,5,29,13,14,24,26,21,17]$ and the summative which is completed after teaching has ended [12, $11,5,29,13,14,24,26,21,17,18]$.

The teacher, however, focuses on the intermediate and summative assessments, because these two will basically influence his/her overall evaluation of the student's performance in the subject (s)he has taught him/her. With the intermediate assessment, it is primarily the student's participation in the teaching process that is assessed together with the so-called "presentation" of the syllabus in class, while his/her summative performance is assessed with the final assessment. His/her summative performance, however, responds to what (s)he has learnt from the lesson, while his/her participation in the lesson is an "achievementparticipation" or a participation achievement (i.e. the degree and approach of participation in the lesson) - see how actively, in what way or ways and with how positive results for the teaching process as a whole (s)he participated in the lesson $^{8}$.

Turning back to our analysis, emphasis is given on the individual components of a student's performance, which is assessed by the teacher, expressing concerns regarding certain issues arising from quite a few of them.

So the components of performance which the teacher is called upon to assess are no longer included in the classic "framework", knowledge - attitudes - skills [16, 22, 6], but in a more complex one, which is more analytical and, possibly more "comprehensive" in terms of "information". More specifically, these components are the following:

(1) The student's knowledge [14] - either acquired after teaching (see summative assessment), or that which (s)he had already had before the commencement of teaching (see diagnostic assessment). Here, however, there is an issue arising: Not all students have the same lingual-expressive ability (and here we do not have in mind any possible stuttering or other relevant problems students may be facing), since others have a good command of speech while others do not. Others are eloquent and/or have a rich vocabulary, but others do not. Finally, some students can structure their thoughts well in oral speech, while others cannot. Apart from these ascertainments, the type of examination (oral - written) which forms the basis for the assessment also plays a significant role. In other words, some students express themselves well in written speech and some others express themselves

8 E.g. a student may answer to all questions posed by the teacher during his teaching, but be so disruptive that (s)he creates pedagogically unfavourable conditions in class; therefore, in this case, his/her teacher's assessment (qualitative or expressed in marks) may (fairly or unfairly) not be so "positive". better orally. (There are still those who express themselves equally well in both forms of speech.) Moreover, other students need more time to turn their thoughts into speech (either written or even oral), and others can do so even when they do not have a lot of time on their hands. ${ }^{9}$ Therefore, isn't the teacher influenced sometimes -perhaps many times- even by the student's "inability" to express him/herself in such a way as to somewhat underestimate his/her cognitive performance? Besides, note that in some subjects the quality of a student's speech plays an even more determining role -see, e.g. not only philological subjects, but also subjects like Religion and Sociopolitical Education-, as it considerably affects the accuracy and wealth of his/her views and the answers (s)he gives to the teacher's questions. E.g. in every scientific Social Science project -with the exception, perhaps, of the case when this is an exhibition/presentation of some purely quantitative research data-, its scientific discourse coincides with the lingual discourse. I.e. the scientific element corresponds with the textual element. In other words, the scientific discourse of the special expect coincides with the lingual discourse that (s)he him/herself has and articulates as the writer-author. Thus, if the special scientist's speech is not accurate, clearcomprehensible and vivid, (s)he cannot convince people of his/her scientific accuracy, truth, validity and value. Hence, in a few words, (s)he cannot even convince people of his/her scientific standing. And, in our opinion, this is something that every teacher teaching theoretical subjects should explain emphatically to his/her students; in sciences and subjects which demand quality, clarity and accuracy of lingual expression on the part of students, when they answer one of their teacher's questions or take part in a discussion in class (and it is within this framework of accuracy that the choice of the appropriate words or necessary terms-words is included), accuracy is considered to be the only, real and authentic reflection of the quality of content and the student's way of thinking, that is whether and how well-correctly or deeply the students have understood what they read or were taught.

(2) The various kinds of cognitive competencies of students, which are divided between those which

9 At this point it would be useful to remember the shared findings arising from relevant research projects in Greece and abroad (see about them in [5]), that the overwhelming majority of teachers do not lend their students sufficient time to talk or answer questions in class, since, either consciously or unconsciously, they insist that they express their opinion or answer in just a few seconds. But, as is known, analytical sentences and views, which express well-structured and rich reasoning, need some sufficient time to be articulated orally. And the kind of thinking (and also speech) that sociopolitical science subjects should promote is substantially based on such rich (in content, quality and also length) reflections. Therefore, it can immediately be perceived how necessary it is for a teacher to provide sufficient time to his/her students to elaborate on their views regarding the subject (s)he teaches. 
allow him/her to perceive and comprehend the knowledge taught-"syllabus" and which is called perception (see how well-deeply and quickly (s)he understands and consolidates what (s)he listens in class or what (s)he reads) and those that allow $\mathrm{him} /$ her to make fast and effective use of the material (:knowledge and information) (s)he is taught and also combine it with input from other modules or fields of reality or everyday life. (Therefore we refer to the speed and quality of a student's perception and thinking.) And these can be called capabilities to capitalise on the knowledge acquired. Such competencies can be found e.g. in someone who expresses him/herself sufficiently or can use examples which are in support of what (s)he says. Hence, the teacher finally assesses the student, consciously or unconsciously, also on the basis of his ability to use language and express him/herself [14]. But also whoever "participates" easily and effectively in the teaching phase, which is called application. ${ }^{10}$ And application includes doing exercises, solving problems, using theoretical knowledge on the level of practical applications (in laboratory classes or othersee, for example, the case of technical vocational education) and other similar cases; in other words, capitalising on knowledge that has just been acquired, in real conditions, which means in alanysing and interpreting real phenomena and/or solving problems that everyday life triggers (in the sphere of labour, society or even science).

These competencies also include the so-called critical competency of the student, ${ }^{11}$ i.e. his/her (general) critical thinking-perception, within the framework of which the competent student (not the one who, simply and only, has his/her own opinion and the courage to express it in class) can assess phenomena, situations, facts, thoughts, arguments, predictions, views, suggestions and ideologies in a solidly justified manner. (When it comes to sociopolitical subjects, it is considered crucial that the student has the following competency: to use convincing arguments on various issues $[1,3]$. And, note, that this competency presupposes, at the same time, three "more special" competencies, already mentioned above: fluency/eloquence, critical thinking and, usually, "speed" of thinking.)

(3) c)The student's way-kind of thinking. More specifically, what is assessed is whether the student has (i)creative thinking ${ }^{12}$ (in recent years there is a lot of discussion about it and the need to develop it amongst students) and original-innovative (see the so-called deviant thinking $[9,10])$. In i we may also include the student's imagination - i.e. how imaginative (s)he is and how creatively (s)he uses imagination in relation to

10 See about this, for example, in $[25,12,7,23,15]$.

11 See about this, for example, in [2, 4] and about critical thinking see, for example, in $[9,7]$.

12 See about this, for example, in [10, 27], where the unclear meaning of creativity, at least in the field of pedagogical sciences, is underlined. what (s)he is taught at school.

(ii) Whether a student can think and perceive things easily, in a subtractive manner. Moreover, whether his/her way of thinking can be (iii)penetrating-deep (iv)analytical (that is, if the student can easily analyse a phenomenon in its individual components-pillars or a theory or ideology in its individual constituents-positions).

Moreover, (v)if (s)he is combinatorial -if, that is, the student can associate knowledge and information (s)he has acquired in previous modules of the same subject, and even some he has acquired from other-different subjects- (see, for example, the association of knowledge from Physics with that from Chemistry, or History with knowledge of Political Science or Political Theory).

Finally, (vi)whether (s)he is combinatorial (if (s)he can, in other words, form a cohesive whole out of a set of data (s)he was provided with during the lesson and ascertain the relations that exist amongst it, or suggest a kind of relation amongst them that would satisfy a specific criterion (s)he was given, or the need to present a specific function, or the solution of a "problem", or exercise). However, items ii, iii, iv, $\mathrm{v}$ and vi, as different kinds of thinking, can also be included in $b$, which relates to a student's perception competencies. But they were not included in $b$ because all kinds of thinking included in $\mathrm{c}$ are regarded as equally important - i.e. as different, but of equal value (in terms of quality), despite the fact that some of them have a higher "value" in the field of certain kinds of sciences or (professional or other) activities and a lower one in the field of some other - see in the next paragraph. Hence, at this point, our perspective is similar to Gardner's about the multiple intelligences [8] which he considers to be "equally important".

What should be stressed here, however, as it is the most important of all, is the following: As is known, certain kindsways of thinking serve a particular kind and sector-field or branch of sciences more, while some other kinds serve another kind and sector or branch. Besides, every science constitutes much more a particular way to perceive, analyse and explain reality, rather than a large corpus of accumulated knowledge and information or data. (This is where the importance that all scientists and philosophers of sciences attribute to the special method or methods via which each science processes its subject matter.) Thus, in order for a student to have more chances to progress in, e.g., theoretical or social sciences, it is much more necessary to have subtractive thinking than to have an original and creative way of thinking. On the contrary, in order to progress in the sciences of Communication and Advertising, (s)he will be aided much more from a creative and deviant way of thinking rather than from a subtractive way of thinking. Finally, in order for someone to progress as a doctor, (s)he will need to have a combinatorial way of thinking much more than a subtractive way of thinking. On the contrary, if someone wishes to be a good engineer, he will definitely need to have an advanced analytical and combinatorial way of thinking, rather than a subtractive and innovative one. (However, in order for someone to be 
exceptional and a pioneer in any science (s)he decides to serve, (s)he should have also developed the way of thinking that responds to deviant-creative thinking, amongst others). Hence, the teacher of sociopolitical science subjects at school should evaluate a student's feature to have subtractive and penetrating, or justifiably critical thinking, rather than, e.g. deviant, as particularly positive.

(4) d)A student's skills ${ }^{13}$ relate to handling tangible data in a way that requires a sharp eye or good and accurate kinesiology of the body and hands or very careful and acute sense of hearing (perhaps also smell or taste, as needed in cookery training). And such skillscapabilities $^{14}$ that respond to abilities of the senses and fine handling of the body, but also keen observation, are mainly required in artistic education that relates to the cinema, dance, music and the visual arts, and also technical vocational education.

(5) e)A student's behaviour [14] during the lesson ${ }^{15}$ and, more specifically, the way (s)he participates in it. In this case, of course, it is obvious that this quality is not countable (therefore it is not evaluated-valuated easily ${ }^{16}$ ) and which, most probably, is even more closely attached to the teacher's subjectivity. E.g. a teacher may consider it very important or even necessary that his/her students participate in the lesson - therefore (s)he considers it a very negative point in his/her student's assessment that this student does not take part in the lesson. Another teacher, however, may not consider it so necessary or important. In addition, it depends, to a great extent, also on the kind of subject, while it often depends also on the level of the subject (and also, of course, on the cognitive background of the students that make up a class). More analytically, in approximately $50 \%$ of the cases, a student's participation in the lesson presupposes that (s)he has some, even imperfect or "wrong", knowledge related to the module in question/syllabus. In the subject of Chemistry, however, for example, it is almost impossible for an average student to have knowledge about a chemical phenomenon (or a chemical reaction or the way a chemical product is prepared), before (s)he is taught something relevant at school. Thus, his/her participation is limited to that phase of teaching when the chemical reaction is presented on the board, as he cannot participate "intrusively" in its initial phase

13 Some of these are cognitive while others are social, according to [18].

$14 \mathrm{See}$, for example, about the content of skills which constitute a "classic" teaching objective within the framework of the Teaching Science and Theory, in [15].

15 As it will become evident from what is discussed later, the term behaviour, here, does not refer to "the student's overall behaviour during the lesson" which becomes the object of observation in the assessment method through the systematic observation of a student's behaviour. About this (method) see in [7]. 16 Many have stressed that student assessment relates also to student components that cannot be quantified-measured (see, for example, in [12]). But thinking about it more deeply, don't b, c, d and e, which have been presented so far, seem to be qualities which are rather not evaluated quantitatively? (The same applies for what will be attributed to $f$, which follows.) when the subject is theoretical. Moreover, while it is not so difficult for a 15 -year-old student to participate by "intruding" when a module related to Economy is taught as part of the Political Education in the early classes of Senior High School, where only some economic phenomena are mentioned without being analysed on the basis of some (micro- or macro-) economic theory or according to some (arithmeticmathematic) applied economics formulas, (s)he cannot do so when (s)he is taught Economics in the final Class of Senior High School (unless he has acquired that knowledge from some tutoring lessons) because in this class the level of analysis that is set in the subject of Economics is higher.

Participation in class, however, also includes a student's active listening. So a student who does not participate verbally in teaching, but attends it with attention and concentration, may probably be assessed more positively compared to another student who is often distracted during the lesson, as the teacher has realised.

Moreover, it is obvious that a student's behaviour in class often affects his/her assessment negatively if (s)he is disruptive. Finally, another feature that makes a teacher assess a student positively is how co-operative (or, compliant) (s)he is, both with his/her classmates and the teacher him/herself. (His/her relationship with his/her classmates, however, comes to the foreground only if the teacher assigns group projects to his/her students. Therefore, such a feature can be evaluated only in the case when the teacher has adopted a co-operating approach to teaching with an emphasis on teamwork.)

Hence, , as it can be ascertained, at this point, in the field of assessment many important qualities of students are examined, which derive directly from their very personality and, given the fact that they are evidently qualitative, they cannot be assessed quantitatively/numerically. One of these qualities, for example, is a student's much-praised diligence $^{17}$, i.e. how diligently (s)he completes his/her assignments; e.g. how attentively (s)he does his/her projects or the exercises (s)he is assigned with. Another aspect of what we have called diligence, which is a more important quality of his/her behaviour, is his/her consistency, i.e. how consistent (s)he is to what his/her teacher asks from him/her. For example, does (s)he deliver his/her assignments on time? And his/her consistency is important because it corresponds to a commitment in relation to his/her teacher.

All the above, however, even if it is clear that they should be assessed by the teacher, cause him/her great discomfort when (s)he is called to evaluate his/her students' performance and diligence -or what we have called "behaviour"- using marks.

And f)a student's social (and/or political) views, values and attitudes [18]. Here, there is a very crucial issue arising, particularly as regards the sociopolitical education subjects. A

17 See in [25] about the fact that a student's assessment also includes his/her diligence. 
student's attitudes, which must be of interest to those who teach sociopolitical education subjects, relate to his/her flairs and positions when it comes to certain situations (see, for example, the use of violence against minorities and general criminal activity), or some social, religious, cultural or national groups. So, within the framework of political education offered today in schools of countries where the dominant political culture is democratic, the teacher should cultivate democratic and humanitarian values, attitudes and views among students. In that respect, (s)he should promote positive, or, at least, not negative attitudes towards the various social or minority groups we have just mentioned and, of course, attitudes that would be against violence, criminal activity and intolerance, and also a critical, and finally, negative attitude towards every kind of chauvinism, racism or sexism. Hence, how should a teacher assess the content (or orientation) of political and/or social thinking and the sociopolitical positions-opinions and views of those teenagers who are not in favour of democratic values (see, e.g., the case of students who express nationalistic views), tolerance towards the fellow man who is diverse from us, humanitarianism and social solidarity? If, of course, the teacher him/herself happens not to be a supporter of the aforementioned anti-chauvinistic, anti-sexist, anti-racist, democratic and humanitarian values and views, the question can be easily answered: (S)he will apparently assess favourably those students who have opinions similar to his/her, or, most probably, (s)he will not assess them negatively as a result of their very views and positions. If, though, (s)he has democratic, humanitarian and antichauvinistic views, will (s)he be influenced, to a certain extent, negatively from the differences of opinion with his/her students in the assessment (s)he will make of them or not? The answer we consider appropriate here is the following: (S)he should not be influenced negatively in his/her assessment, but (s)he should consider attempting even more systematically, but not in a way that would appear "pressing", to make his/her students perceive reality in a different and more human, tolerant and democratic way.

\section{Conclusion}

Concluding, it should be stressed that, in any case, teachers of sociopolitical school subjects must not forget that their subjects do not only entail information or knowledge, but also attitudes, values and views/beliefs; such that fall within a field of sociopolitical ethics (which relates to acting correctly, speaking correctly and thinking and perceiving correctly) that expresses also a specific positive social assessment regarding certain important, for the social and political life, issues and stakes which are linked, from a social perspective, with democracy and tolerance towards the politically and ideologically different/"other" and, from a social perspective, with humanitarianism and solidarity towards those who suffer and any fellow man who experiences some form of social exclusion. Therefore, the role and pedagogical, social and, finally, political duty of this teacher is to offer students a kind of education that would also relate to edification (in the sense of indicating orientation to underage students - see the origin of the Greek word for edification ( $\alpha \gamma \omega \gamma \eta$ ) from the verb $\alpha \gamma \omega$, which means "show the way"), and also that of education, which, however, includes cultivation of certain competencies which will allow them to have a democratic and critical political thinking, and also some skills which will make them capable of participating in an active, effective and creative way (i.e. with a "positive" contribution to society) in the social developments when they become adults.

Assessing the "result" of a teacher's teaching task, however, which is reflected on the learning result expressed through the thinking, behaviour and, finally, the overall political culture that the student will have "acquired", should be completed by the teacher on the basis of the sociopolitical values mentioned above. Because, finally, the reason behind the assessment conducted within the framework of these subjects is to conclude in an ascertainment whether and to what extent the student has finally internalised these very values. Besides, it is a fact that school assessment itself as a process has a social value and, at the same time, constitutes a social value, exactly because -or on condition and only on condition that- it evaluates the degree to which values are reflected in the face of students; those values that the society where the given school operates "believes" in.

\section{References}

[1] Baltas, C. (2010). Kinonikos kai politikos egrammatismos: to paradigm ton neon vivlion Kinonikis kai Politikis Agogis stin protovathmia ekpedefsi (Social and political literacy: the example of the new Social and Political Education books in primary education). Synchroni Ekpedefsi, 163, 54-70.

[2] Bikos, G. D. (2018a). On Teaching Objectives and the Teaching Methodology of Sociopolitical Education Subjects, Swift Journal of Social Sciences and Humanities, August 2018, vol. 4 (2), pp.23-27.

( http://www.swiftjournals.org/sjssh/pdf/2018/august/Bikos.pdf )

[3] Bikos, G. D. (2018b). On Teaching Political Education Subjects in Secondary Education", International Journal of Humanities, Social Sciences and Education, vol. 5, issue 7, 2018, pp.150-156. DOI: http://dx.doi.org/10.20431/23490381.0507017

[4] Bikos, G. D. (2015a). Introduction. In G. D. Bikos (ed.), "I dimokratiki agogi: didaskontas, ekpedevontas, kalliergontas..." ('Democratic Education: Teaching, Educating, Cultivating...') Minutes of a Conference organised by the Experimental General High School of Ionidios School of Piraeus 27-29/9/13. Athens: Grigoris Publications (pp.21-29).

[5] Bikos G. D. (2015b). Developing critical political thinking and shaping active citizens: the basic principles of a proposed teaching approach. In G. D. Bikos (ed.), "I dimokratiki agogi: didaskontas, ekpedevontas, kalliergontas..." ('Democratic Education: Teaching, Educating, Cultivating...') Minutes of a Conference organised by the Experimental General High School of Ionidios School of Piraeus 27-29/9/13. Athens: Grigoris Publications (pp.259-269). 
[6] Bikos G. D. (2014). Editor's introductory note. In G. D. Bikos and A. Kaniari (ed.) Mousiologia, Politistiki Diahirisi kai Ekpedefsi (Museology, Cultural Management and Education). Athens: Grigoris Publications. (pp.69-76).

[7] Chaniotakis, N. I. (2007). I ipovoli erotiseon apo tous mathites: diapistosis kai dinatotites veltiosis (Questions posed by students: conclusions and prospects for improvement). In Evi MakriBotsari (ed.), Issues of initial training for newly-appointed teachers. Athens: Greek Ministry of Education, Research and Religious Affairs-Pedagogical Institute (pp.24-36). (retrieved from schools.gr/download/news/t_eisag_epimorfosis.pdf) http://www.pi-

[8] Christias, I. (1992). Theoria kai methodologia tis didaskalias (Theory and methodology of teaching). Athens: Grigoris Publications.

[9] Dimitropoulos, E. G. (2007). Ekpedeftiki axiologisi: meros deftero - i axiologisi tou mathiti: theoria - praxi - provlimata (Assessment in education: second part - student assessment: theory - practice - problems). Athens: Grigoris Publications.

[10] Gardner, H. (1991). The unschooled mind: How children think and how schools should teach. London: Fontana Press.

[11] Holden, C. (2000). Learning for democracy: From world studies to global citizenship. Theory into Practice, 39 (2), 74-80.

[12] Kapetanakis, G. D. (2017a). Tropi anaptixis tis kritikis skepsis meso tis didaskalias ton Thriskeftikon (Ways to develop critical thinking through teaching Religion). In G. D. Kapetanakis, G. A. Kouyioumtzis, G. D. Bikos (ed.), Sinchrones prosegisis sti Didaktiki ton Thriskeftikon (Modern approaches to Teaching Religion). Athens: Grigoris Publications (pp.47-58).

[13] Kapetanakis, G. D. (2017b). I anaptixi tis dimiourgikis skepsis meso tis didaskalias ton Thriskeftikon (How to promote critical thinking through teaching Religion). In G. D. Kapetanakis, G. A Kouyioumtzis, G. D. Bikos (ed.), Sinchrones prosegisis sti Didaktiki ton Thiskeftikon (Modern approaches to Teaching Religion). Athens: Grigoris Publications (pp.73-83).

[14] Kapsalis, A., Chaniotakis, N. (2011). Ekpedeftiki axiologisi (Assessment in education). Thessaloniki: Kyriakidis Bros Publications.

[15] Kassotakis, M. (2013). I axiologisi tis epidosis ton mathiton: Theoritikes prosegiseis kai praktikes efarmoges (Assessing student performance: Theoretical approaches and practical applications). Athens: Grigoris Publications.

[16] Konstandinou, H. (2002a). I axiologisi tis epidosis tou mathiti simfona me to Diathematiko Enieo Plesio Programmaton Spoudon (Assessing student performance on the basis of the Interdisciplinary Unified Curriculum Framework). Epitheorisi ekpedeftikon thematon (Review of educational issues). Vol. 7, pp.37-51.

[17] Konstandinou, H. (2002b). I axiologisi tis epidosis tou mathiti os pedagogiki logiki kai sholiki praktiki (Student performance assessment as a pedagogical logic and school practice). Athens: Gutenberg.

[18] Korhonen, R., Lestinen, L. (2009). Learning Citizenship Education in University: Views and Experiences of Finnish Class Teacher Students. In A. Ross (ed.) Human Rights and Citizenship Education (pp.359-363). London: CiCe - Children's Identity and Citizenship in Europe.

[19] Kouyioumtzis, G. A. (2017). Shediasmos didaktikis stohothesias kai Arhaia Ellinika: apo tin taxinomia tou Bloom sto modelo tou romvou (Designing teaching objectives and Ancient Greek: from Bloom's taxonomy to the diamond model). In G. A. Kougioumtzis, G. D. Bikos, G. Papadimitriou (ed.), Didaskontas Arhaia Ellinika (Teaching Ancient Greek). Athens: Grigoris Publications (pp.69-86).

[20] Matsagouras, I. G. (2000). Theoria kai praxi tis Didaskalias (Theory and practice of Teaching) Vol. B: Stratigikes didaskalias: I Kritiki Skepsi sti Didaktiki Praxi. (Teaching strategies: Critical thinking in the Teaching Act). Athens: Gutenberg.

[21] Pamouktsoglou, A. I. (2007). Theoria, praxi kai axiologisi tis didaskalias (Theory, practice and assessment of teaching). Athens: Ellinoekdotiki.

[22] Pamouktsoglou, A. I. (2005). Ekpedeftiki axiologisi (Assessment in education). Athens: Diinekes.

[23] Pamouktsoglou, A. I. (2003). Axiologisi kai sholikos simvoulos (Assessment and school advisors). Athens: Synchroni Ekdotiki.

[24] Papadimitrakopoulos, V. (2006). Gia mia esoteriki axiologisi tis sholikis monadas (On an internal assessment of the school unit). Epistimoniko Vima tou daskalou, vol.6, pp.43-59.

[25] Papanaoum-Tzika, Z. (1985). I axiologisi tis sholikis epidosis: dinatotites kai oria (School performance assessment: capabilities and limits). Thessaloniki: Kiriakidis Bros Publications.

[26] Papas, A. (1996). Mathitokentriki Didaskalia, 2: To pedagogiko klima sto Anichto Sholio - Didaktika kai mathisiaka modela (Student-centered Teaching, 2: The pedagogic climate in the Open School - Teaching and learning models). Athens: Vivlia gia olous.

[27] Petsimeri, I. (2005). Didaktiki Methodologia: Didaktiki ton Archeon Ellinikon (Teaching Methodology: Teaching Ancient Greek). Athens: Grigoris Publications.

[28] Rekalidou, G. (2011), Axiologisi tis mathisis i axiologisi gia ti mathisi? (Learning assessment or assessment for learning?). Athens: pedio.

[29] Rellos, N. (2007). Elenhos mathisis - axiologisi mathitikis epidosis (Learning report - school performance assessment). Athens: Gutenberg.

[30] Taratori-Tsalkatidou, E. (2015). Sholiki axiologisi (School assessment). Thessaloniki: Kyriakidis Bros Publications.

[31] Tsikopoulou, S. (2017). Antilipsis ton ekpedeftikon gia ti dimiourgikotita sta mathimatika (Teachers' views on creativity in mathematics). Erkyna: Review of Educational-Scientific Issues, Vol. 12, pp.34-47.

[32] https://erkyna.gr/e_docs/periodiko/teyxos/teyxos-12(12_2017).pdf

[33] Vainas, K. (2008). Isagogi stin Epaggelmatiki Pedagogiki (Introduction to Professional Pedagogy). Athens: Gutenberg.

[34] Vlachos, I. A. (2004). Ekpedefsi stis Fysikes Epistimes - I protasi tis epikodomisis. (Education in Natural Sciences - The proposal of constructivism). Athens: Grigoris Publications. 